\title{
O Processo de Aprendizagem do Residente de Anestesiologia: uma Reflexão sobre o Cuidado ao Paciente
}

\author{
The Learning Process for Residents in \\ Anesthesiology: Reflections on Patient Care
}

Leonel Alves do Nascimento ${ }^{I}$ Cibele Cristina Tramontini ${ }^{I}$ Mara Lúcia Garanhani ${ }^{1}$

\section{PALAVRAS CHAVES: \\ - Residência Médica \\ - Anestesiologia \\ - Assistência Médica \\ - Assistência ao Paciente \\ - Relações Médico-Paciente \\ - Pesquisa Qualitativa}

\section{KEYWORDS:}

- Internship and Residency

- Anesthesiology

- Medical Assistance

- Patient Care

- Physician-Patient Relations

- Qualitative Research

Recebido em: 23/06/2010

Reencaminhado em: 24/08/2010

Aprovado em: 16/02/2011

\section{RESUMO}

Pesquisa descritiva de abordagem qualitativa. O objetivo do estudo é identificar o cuidado com o paciente cirúrgico dispensado pelo residente de anestesiologia e o compartilhamento deste cuidado com a equipe cirúrgica, bem como as percepções desse residente sobre o autocuidado. A análise dos discursos dos nove residentes entrevistados resultou na construção de seis categorias: (a) escolha da especialidade: proximidade com o intensivista, imediatismo das ações e analgesia; (b) cuidados com o paciente cirúrgico: apresentação de ações de rotina e da técnica anestésica empregada; (c) compartilhamento do cuidado com os outros profissionais: o residente compreende sua importância, mas compartilha pouco; (d) preceptoria médica: existe uma ambivalência de sentimentos - satisfação pela proximidade com o docente, pela orientação e resolução de problemas, e insatisfação pelo pouco tempo dedicado às atividades acadêmicas e despreparo docente; (e) autocuidado: os residentes negligenciam o autocuidado, devido principalmente à extensa carga horária. As repercussões desta postura são relatadas como nervosismo, impaciência, diminuição da criatividade e do humor, e propensão a erros.

This was a descriptive study with a qualitative approach. The aim was to identify the care provided to surgical patients by residents in anesthesiology and how they share this care with the surgical team, as well as residents' perceptions concerning self-care. Discourse analysis of interviews with nine residents resulted in six categories: (a) choice of the specialty: proximity to the intensive care specialist, the immediatism of the activities, and analgesia; (b) surgical patient care: presentation of routine measures and the anesthetic technique employed; (c) sharing of care with other professionals: the resident understands the importance of care, but tends not to share it; (d) medical preceptorship: ambivalent feelings, including satisfaction due to the proximity to faculty, orientation, and problem-solving, and dissatisfaction due to the limited time devoted to academic activities, plus faculty unpreparedness; (e) self-care: residents neglect self-care, due mainly to the exhaustive workload. The repercussions of this attitude are reported as nervousness, impatience, decreased creativity and mood, and propensity to error. 


\section{INTRODUÇÃO}

O médico anestesiologista é o profissional responsável pelos procedimentos anestésicos durante o período perioperatório. Sua especialização garante a competência necessária para que o processo anestésico-cirúrgico seja seguro e eficaz. Para o anestesiologista, a vigilância constante e o estado de prontidão são fundamentais para evitar falhas, que, muitas vezes, podem ser fatais ${ }^{1}$.

A residência médica em anestesiologia é uma especialidade de pós-graduação de treinamento em serviço. Tem duração de três anos e traz para o médico uma gama de conhecimentos e habilidades relevantes a sua especialidade, moldando sua vida profissional ${ }^{2}$. O preparo está pautado no acompanhamento docente, na presença no campo de trabalho e em infindáveis horas de estudo desenvolvidas pela residência.

Atualmente, a medicina apresenta um grande crescimento tecnológico e um aumento exponencial de sucessos nos procedimentos. Espera-se que os usuários também tenham suas necessidades atendidas e que o médico tenha maior efetividade com sua carreira. O aumento da tecnologia na anestesiologia é responsável pela diminuição do número de complicações decorrentes do processo anestésico. Nesta perspectiva, o cuidado de forma integral ao paciente também tem acompanhado o crescimento dos instrumentos tecnológicos na anestesiologia?

Sabe-se que o desenvolvimento das ciências médicas e das novas técnicas de diagnóstico e tratamento contribui para o crescimento de um modelo biomédico centrado na doença, que dificulta a participação ativa do paciente, muitas vezes nem considerado na tomada de decisão e informação ${ }^{3}$.

Sabe-se também que um dos principais medos do paciente está relacionado ao procedimento anestésico. Isto faz do profissional anestesiologista uma peça-chave no cuidado do paciente, pois desmitifica as técnicas e medicamentos que serão utilizados, garantindo, assim, a tranquilidade, a colaboração e a satisfação do cliente ${ }^{4}$.

Portanto, a realização desta pesquisa é baseada nas seguintes indagações: de que forma o residente em anestesiologia percebe o cuidado ao paciente? Como ele se cuida? Como ele se sente cuidado pelos professores?

Para responder a estas indagações, estabeleceram-se os seguintes objetivos: descrever o cuidado com o paciente cirúrgico dispensado pelo residente de anestesiologia; identificar o autocuidado realizado pelo residente de anestesiologia; relacionar as percepções do residente de anestesiologia sobre o compartilhamento do cuidado ao paciente com a equipe de saúde e identificar como ele se sente cuidado pelo docente.

Acreditamos que, para que possa cuidar de forma humanizada do paciente, o residente necessita primeiro com- preender seu processo de trabalho e exercer um autocuidado eficaz, pois o distanciamento entre o profissional e o paciente pode levar à desumanização do cuidado. Espera-se que este trabalho contribua para que os profissionais da área da saúde repensem suas práticas, para investir em um cuidado humanizado ao paciente.

\section{METODOLOGIA}

Trata-se de uma pesquisa descritiva, com abordagem qualitativa. O local do estudo foi um hospital universitário.

A pesquisa qualitativa é concebida como uma trajetória circular em torno do que se deseja compreender, não se prendendo a princípios, leis e generalizações, mas voltando-se a olhar para a qualidade e os elementos significativos para o observador-investigador. Não existe neutralidade do pesquisador em relação à pesquisa, pois ele atribui significados, seleciona o que o mundo quer conhecer, interage com o conhecido e comunica sua construção de resultados, entendendo que suas observações não são fechadas e nunca serão definitivas ${ }^{5}$.

O recurso utilizado para a coleta de dados foi uma entrevista semiestruturada, que possibilita captar os diferentes discursos, atendendo aos objetivos do pesquisador, definidos a partir de hipóteses e suposições advindos da elaboração dos objetivos do estudo ${ }^{6}$.

As perguntas orientadoras utilizadas na entrevista com os residentes de anestesiologia foram: Qual o seu nome? Qual a sua idade? Fale-me sobre sua formação. O que significa cuidado para você? Quais as necessidades de cuidado que você considera que o paciente cirúrgico apresenta? Como você cuida do paciente no pré-operatório, no intra e no pós? Como você compartilha o cuidado do paciente cirúrgico com os outros membros da equipe cirúrgica? Como você acha que a equipe cirúrgica deve estar preparada para cuidar? Como você se sente cuidado pelo docente que o acompanha? Como você se cuida?

O número de participantes a serem entrevistados numa pesquisa qualitativa se define a partir do momento em que surgem as convergências e repetições nos discursos coletados.

Nesta pesquisa, optou-se por entrevistar a totalidade dos residentes, pois o quadro de residentes é constituído por nove médicos, distribuídos nos três anos de duração da residência.

Quanto aos aspectos éticos da pesquisa, o projeto de pesquisa deste estudo faz parte de um projeto maior, denominado "O cuidado perioperatório - o significado para o paciente, familiares, equipe de saúde e alunos", aprovado pelo Comitê de Ética em Pesquisa da instituição, conforme o parecer CEP no $122 / 08$.

Após esclarecimentos sobre os objetivos do estudo, a metodologia utilizada e a necessidade de gravação das entrevis- 
tas, os residentes assinaram o Termo de Consentimento Livre e Esclarecido.

Após as entrevistas, realizou-se a transcrição na íntegra e em seguida foram retirados os vícios de linguagem, possibilitando uma leitura contínua das experiências dos sujeitos envolvidos. No trabalho, os sujeitos estão apresentados com a consoante $\mathrm{R}$ para os discursos dos médicos residentes, seguida pelo número da entrevista, que foi escolhido aleatoriamente.

Para a análise dos dados, foi utilizada a sequência proposta por Martins e $\mathrm{Bicudo}^{7}$, composta por dois momentos. O primeiro é a análise ideográfica, referente à inteligibilidade dos significados presentes, que se articulam em suas inter-relações e em sua unidade estrutural. No segundo momento, a análise nomotética, relacionada à construção dos resultados, à compreensão e à elucidação do fenômeno estudado.

No primeiro momento, foram feitas várias leituras flutuantes para se familiarizar com a linguagem dos residentes participantes da pesquisa. Em seguida, foram destacadas através de grifo as frases ou palavras que identificavam as unidades de significado que respondiam aos objetivos propostos nesta pesquisa. Na sequência, estas unidades de significado foram interpretadas e agrupadas quando apresentavam semelhanças. Desta forma, conclui-se a análise individual ou ideográfica.

Para a concretização da análise geral, foi feita a aproximação de todas as unidades de significado interpretadas dos nove residentes participantes da pesquisa. Nesse momento, foram analisadas não mais na sua individualidade, mas como parte do todo do fenômeno ser residente de anestesiologia. Esta aproximação resultou na construção de seis categorias: escolha da especialidade; como o residente cuida do paciente cirúrgico; compartilhando o cuidado com a equipe; preceptoria médica; prática do autocuidado; repercussões do processo de trabalho no cuidado com o paciente.

\section{RESULTADOS E DISCUSSÃO}

Participaram desta pesquisa nove residentes de anestesiologia distribuídos nos três anos de duração da residência. O grupo de residentes consistia em sete homens e duas mulheres, com média de idade de 27 anos. Oito dos residentes foram formados na mesma instituição onde estão cursando a residência e apenas um foi formado em outra instituição. Seis médicos entraram no programa de residência logo após sua formação e três após um ano de formado.

O processo de trabalho em saúde se diferencia de outras áreas por, ao invés de produzir um produto, ser uma prestação de serviço, cujo resultado final é o cuidado em saúde. Para produzir cuidado, o médico tem a sua disposição três "vali- ses": uma corresponde a sua caixa de ferramentas, ou seja, às tecnologias duras; a segunda, aos saberes estruturados, tais como a epidemiologia e clínica, e tecnologias leves-duras; a última "valise" contém tecnologias leves implicadas com a produção das relações entre o médico e o paciente ${ }^{8}$.

É nas relações entre o trabalhador e o usuário que ocorrem os processos produtivos do cuidado. Neste encontro, o médico assume e realiza a produção do cuidado ao paciente, utilizando suas "valises"

$\mathrm{O}$ residente em anestesiologia tem dois processos distintos em seu ambiente de trabalho. Ao mesmo tempo em que produz cuidado ao paciente, o residente, por meio das atividades acadêmicas e do acompanhamento de seu preceptor, adquire e desenvolve a competência de cuidar. Podem-se observar diferentes processos de trabalho que culminam com o funcionamento de toda a estrutura hospitalar, finalizando com o cuidado e a formação do aluno/residente.

Os discursos dos nove residentes participantes desta pesquisa possibilitaram a construção de seis categorias: escolha da especialidade; como o residente cuida do paciente cirúrgico; compartilhando o cuidado com a equipe; preceptoria médica; prática do autocuidado; repercussões do processo de trabalho no cuidado com o paciente.

A primeira categoria construída aborda os motivos da escolha da especialidade anestesiologia. De acordo com os discursos, essa escolha foi motivada pela proximidade com a medicina intensiva, pela oportunidade de se dedicar a um único paciente, pelo imediatismo das ações e pelo controle da dor.

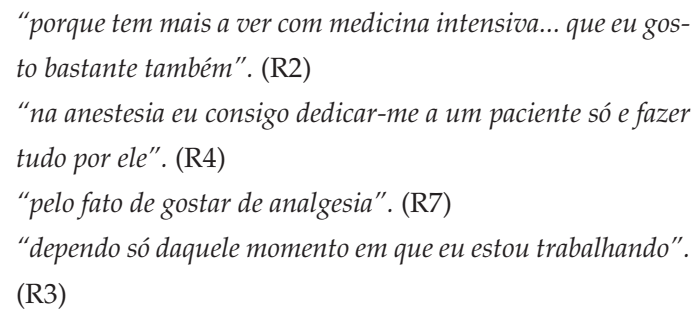

A presença do poder e do prestígio na representação social do médico é clara. Uma etapa importante na busca por este destaque e distinção é a escolha da especialidade médica. A especialidade é o encontro do homem/médico com seu trabalho. O relacionamento com o paciente é um dos fatores causadores de ansiedade e aflições ao jovem médico. $\mathrm{O}$ fato de se dedicar a um único paciente, acompanhando apenas uma pequena trajetória de sua internação, pode se apresentar como uma estratégia interessante ao jovem médico, pois assim ele pode cuidar de todas as necessidades do paciente naquele momento?. 
A analgesia e a dedicação exclusiva a um único paciente são características existentes na residência em anestesiologia, e muitos jovens médicos escolhem esta especialidade por estas características.

No Brasil, a especialização em medicina intensiva tem como pré-requisito o término da residência em clínica médica, cirurgia geral ou anestesiologia. A falta de profissionais especializados em medicina intensiva e a remuneração são um indicativo de peso na escolha da especialidade ${ }^{10}$.

A segunda categoria construída retrata como o residente cuida do paciente cirúrgico. Esta categoria reúne os relatos dos residentes de anestesiologia sobre as ações de cuidado oferecidas ao paciente e sua família durante o perioperatório. Os cuidados relatados estão relacionados a ações de rotina, e o cuidado é baseado em técnicas e normas estabelecidas de acordo com a necessidade do procedimento cirúrgico, da técnica anestésica adotada e do paciente.

Além destes cuidados, encontram-se as atividades referentes ao período pré-operatório, nas quais o residente realiza a visita pré-anestésica, tendo a oportunidade de examinar o paciente, oferecer apoio emocional, informação e orientação aos pacientes e familiares, além de prescrição de medicações pré-anestésicas e de iniciar uma relação médico-paciente.

Devido à complexidade dos procedimentos cirúrgicos, é fundamental que o anestesiologista conheça o paciente, pois durante a visita pré-anestésica ele "visita e examina o paciente" (R6). A avaliação pré-anestésica objetiva a agilidade e qualidade do atendimento prestado tanto aos pacientes como aos profissionais que trabalham no centro cirúrgico, proporcionando a segurança do procedimento anestésico-cirúrgico e diminuindo a incidência de complicações inesperadas ${ }^{11}$.

O relacionamento médico-paciente estabelece maior responsabilidade do médico perante o paciente. Assim, este cria uma relação de confiança no profissional, colocando nas mãos do médico os diferentes tratamentos, pois sabe que será para seu restabelecimento, "ganhando a confiança dele, em um único momento em que vamos nos relacionar" (R4).

O curto período disponível para a realização da consulta é visto como a principal dificuldade para desenvolver este relacionamento ${ }^{12}$.

A família também deve ser orientada, pois "muitas vezes, está junto com o paciente no pré-operatório" (R3) e sofre ante a cirurgia de seu ente. Um dos benefícios citados pelos residentes é que "principalmente quando ocorre alguma intercorrência, a família já está sabendo do procedimento, sabendo de tudo o que vai ser feito, então é muito mais fácil lidar com isso" (R3).

O paciente e sua família acompanham cada palavra e gesto do cirurgião e anestesista, atentos para observar sinais positivos ou não sobre a cirurgia. A postura deste profissional deve ser segura e serena, estabelecendo, desde o primeiro contato, uma relação de confiança e respeito, visando aos resultados positivos do procedimento. Dedicando-se ao paciente, ouvindo suas queixas, examinando-o, fazendo as prescrições, informando e orientando, esclarecendo sempre as suas dúvidas, o médico o tranquiliza e o integra ao tratamento ${ }^{13}$.

É expressiva a necessidade de modificar a linguagem médica, carregada de jargões e termos técnicos, para uma linguagem mais simples e compreensiva ao paciente, proporcionando uma comunicação efetiva entre este e o médico ${ }^{14}$, pois "lidamos com pacientes de diversas classes sociais, diversos níveis de entendimento, adequando a linguagem ao paciente, melhorando a compreensão para ele" (R4).

A medicação pré-anestésica é considerada uma técnica muito eficaz na redução da ansiedade do paciente durante o pré-operatório. Os residentes relataram que "se o paciente desejar, a gente dá uma medicação pré-anestésica para diminuir um pouco a ansiedade" (R7).

Os cuidados referidos pelos residentes durante o transoperatório se relacionam com a monitorização dos sinais vitais, atenção com o posicionamento cirúrgico, coleta de exames, correção de distúrbios laboratoriais, manejo da dor e avaliação para a alta na sala de recuperação anestésica, garantindo sempre o bem-estar do paciente.

A atenção para o posicionamento incorreto é importante, pois poderá ocasionar dor e lesão no período pós-operatório, como cita o residente: "o posicionamento do paciente, se está correto ou não, se isso vai ocasionar alguma lesão ou gerar dor" (R1), que está, assim, "preocupado com o bem-estar dele no intraoperatório" (R3).

A tecnologia permite que o anestesista acompanhe detalhadamente os parâmetros dos sistemas respiratório, circulatório, neurológico, neuromuscular e alterações de temperatura. Apesar do avanço dos aparelhos de monitorização, a vigilância permanente do paciente pelo anestesista continua sendo mais importante e fidedigna:

"monitorizar, ficar perto do paciente, tomar conta das alterações que acontecem ao longo da cirurgia". (R4)

Durante cirurgias longas e de grande porte, o anestesista "colhe exames laboratoriais" (R7) a fim de observar o estado hidroeletrolítico do paciente. A gasometria arterial e venosa são exemplos destes exames, e seus valores indicam alguma anormalidade na oxigenação, ventilação e no equilíbrio ácido-básico. Estes resultados guiam as condutas do anestesista para "corrigir o distúrbio" (R6). 
As atividades no pós-operatório estão relacionadas com a monitorização e o tratamento de complicações advindas do procedimento anestésico-cirúrgico. Os critérios de alta do paciente são de responsabilidade exclusiva do anestesiologista. Este avaliará a estabilidade hemodinâmica do paciente e ausência de dor, liberando o paciente para o retorno à unidade de internação ou ao seu domicilio, caso seja uma cirurgia ambulatorial ${ }^{15}$.

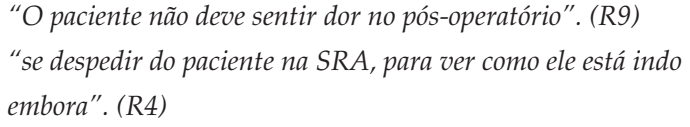

Em instituições públicas de saúde, é comum faltar algum material médico-hospitalar relacionado aos procedimentos anestésicos, ocasionando problemas para a assistência ao paciente. Quanto a isso, os residentes relataram que "a gente briga porque falta cateter de peridural, porque a gente sabe que o paciente vai sentir dor no pós-operatório, e isso faz toda a diferença para o paciente" (R6).

A utilização do cateter peridural é uma forma muito eficaz de analgesia, principalmente no pós-operatório de cirurgias de grande porte ${ }^{16}$.

A falta de materiais decorre de três causas: as estruturais, como baixo investimento e diretores incompetentes; as causas organizacionais, como falta de objetivos claros, falta de capacitação e de atualização pessoal dos diretores, falta de controles internos; e as causas individuais, como a falta de motivação dos funcionários e a existência de diretores improvisados, sem competência para atuar nesta função $\mathrm{O}^{17}$.

$\mathrm{Na}$ terceira categoria deste trabalho, o residente tem a oportunidade de relatar como ocorre o compartilhamento do cuidado com os outros profissionais da equipe cirúrgica.

No dicionário Aurélio, compartilhar significa ter ou tomar parte em, participar de algo. Sabe-se que o paciente cirúrgico apresenta uma série de necessidades que devem ser supridas por uma equipe multiprofissional ${ }^{18}$. $\mathrm{O}$ trabalho em equipe, então, se apresenta como uma ferramenta valiosa no cuidado com o paciente, pois propicia resolver estas necessidades, dividindo as competências e, assim, diminuindo a carga de trabalho de um só profissional.

$\mathrm{O}$ residente entende que, para garantir um atendimento eficiente ao paciente, ele deve compartilhar este cuidado com outros profissionais. $\mathrm{O}$ cuidado é compartilhado com a equipe de enfermagem, por meio da delegação de funções e da cobrança de resultados.

"a gente trabalha muito junto, assim, é partindo, delegando funções". (R2)

\begin{abstract}
"eu acabo cobrando... vocês também têm que me ajudar... a enfermagem é meu olho, meu ouvido e meu nariz, naquilo que está acontecendo com o paciente". (R6)

"trabalhar com uma equipe pode resolver o problema bem mais facilmente do que você sozinho". (R3)
\end{abstract}

No processo do cuidado ao paciente, os profissionais devem buscar o compartilhamento dos cuidados, crenças e valores dos diferentes campos de ação dos trabalhadores do centro cirúrgico. Um aspecto importante é definir qual profissional é o mais importante no cuidado do paciente. Nas falas dos residentes, observa-se uma ambiguidade, pois colocam a enfermagem ora como subordinada, sendo o cuidado "delegado" e "cobrado", ora como parceira, "seu olho, ouvido e nariz".

As dificuldades no trabalho em equipe são relatadas há muito tempo. Pode-se discuti-las em termos da origem do trabalho médico e de sua relação com a enfermagem. As relações sociais são definidas através do poder. Este é exercido por indivíduos que possuem mecanismos elaborados de controle. O médico incorpora este poder, e, para isso, devemos voltar à origem dos hospitais, quando ocorre a introdução de mecanismos disciplinares pelo Exército e Marinha no confuso espaço do hospital. Quando o Exército e a Marinha deixam de comandar o espaço hospitalar, este poder disciplinar é confiado ao médico, devido em grande parte ao crescimento da ciência médica. Esta inversão das relações hierárquicas no hospital e a tomada de poder pelo médico são representadas no ritual de visita médica, em que ele vai à frente do leito do paciente, seguido por toda a escala hierárquica: assistentes, alunos, enfermeiras, etc. Esta codificação do ritual de visita é encontrada nos regulamentos de hospitais do século XVIII, que estabelecem onde cada pessoa deve ser colocada e que a enfermeira deve estar à porta com um caderno nas mãos e deve acompanhar o médico quando ele entrar ${ }^{19}$.

Embora esses procedimentos não sejam mais utilizados na prática e a enfermagem tenha se desenvolvido como ciência, ainda é possível observar resquícios deste comportamento, e o residente de anestesiologia, sendo médico, muitas vezes utiliza mecanismos de poder para distribuir atividades entre a equipe cirúrgica.

O primeiro passo para o cuidado do paciente é reconhecer que todos os profissionais envolvidos com o paciente, independentemente de sua área de atuação, são cuidadores e têm um papel específico ${ }^{20}$.

Os residentes relatam ausência de compartilhamento do cuidado com outras clínicas porque a anestesiologia é uma área extremamente específica: 
"na nossa profissão, a gente consulta muito pouco um profissional de outra área. Como ela é extremamente específica". (R2)

A personalidade reservada, séria, assertiva, tensa e autossuficiente pode ser a causa do não compartilhamento do cuidado, e a especialidade lhes passa a falsa impressão de não necessitar da cooperação de outros médicos. Trabalham sozinhos, temendo a ocorrência de sequelas graves ao paciente, levando-os a só confiarem no próprio desempenho ${ }^{21}$.

Embora relatem a ausência de compartilhamento do cuidado com outras clínicas, os residentes reconhecem que compartilhando é possível realizar o trabalho de forma menos desgastante e com menor sobrecarga. Outro beneficio citado é que esse compartilhamento traz a sensação de cumplicidade entre as equipes:

"se você ficar encarregado de fazer tudo, você consegue fazer, mas se sobrecarrega muito... você pode ligar para o residente da clínica e solicitar algum cuidado... você consegue ver que cria uma cumplicidade, você conta com o cirurgião e ele conta com voce $\hat{e}^{\prime \prime} .(R 7)$

A responsabilidade pelo cuidado em saúde atinge todos os níveis da saúde. É preciso que a equipe de saúde se interrogue acerca do papel que assume perante o paciente, para, assim, repensar seus conceitos e passar a mobilizar suas práticas para um compartilhamento e efetivação do cuidado prestado ao paciente ${ }^{22}$.

A preceptoria médica do residente é a quarta categoria deste trabalho. O jovem médico, durante o período da residência, é acompanhado pelo docente, que lhe ensina as técnicas e faz com que ele alcance competências e habilidades nesta fase de aprendizado. Sobre este acompanhamento, os relatos demonstraram uma ambivalência de sentimentos, coexistindo residentes satisfeitos e insatisfeitos. A satisfação relatada provém da proximidade física com os docentes e da orientação e auxílio que estes dispensam ao residente na resolução de problemas diários, apesar do número reduzido de docentes.

"temos um acompanhamento muito próximo, estamos sempre juntos aqui... eles estão sempre presentes e tentam resolver todos os nossos problemas... apesar do número reduzido de docentes". (R4)

A insatisfação é oriunda de deficiências na área acadêmica, carga teórica insuficiente para a discussão de temas relevantes à especialidade e falta de interesse em relação à formação dos residentes:

\author{
"eu sinto que não somos cuidados... temos poucos temas e a \\ parte teórica é pequena". (R7) \\ "um ou outro docente é que dá mais atenção para a gente... \\ um ou outro que tira nossas dúvidas em relação com o pacien- \\ te... falta de interesse". (R5)
}

O treinamento em serviço sob supervisão em tempo integral constitui, indubitavelmente, a melhor maneira de aperfeiçoamento e especialização em medicina. Autores afirmam que a ausência e o desinteresse dos preceptores tornam muito difícil o período da residência. A ausência da preceptoria foge do conceito inicial que tornou possível a criação do programa de residência, pois o preceptor deve acompanhar o crescimento científico e técnico do residente, além de garantir a segurança dos pacientes atendidos por ele ${ }^{23}$.

O docente médico deve ter capacidade de preparar o residente para aprender de forma a acompanhar a evolução do conhecimento, interagindo com os demais profissionais de saúde, atuando com êxito em equipes multiprofissionais, e, principalmente, buscar atender às necessidades básicas de saúde dos usuários ${ }^{24}$.

Diante destas dificuldades, os modelos tradicionais de ensino-aprendizagem são cada vez mais questionados. A literatura já apresenta métodos de ensino médico - como, por exemplo, a Preceptoria em um Minuto - que têm a atenção voltada ao profissional em formação. Esse método se destaca pela rapidez e pouco tempo disponível para realizar a construção de conhecimentos com o residente ${ }^{25}$.

A quinta categoria trata do autocuidado do residente de anestesiologia. Observou-se nos discursos que os residentes se cuidam muito pouco ou negligenciam por completo o cuidado com seu corpo e mente. A falta de autocuidado é "muito comum no profissional da saúde, não só no médico" (R6).

Diversos motivos levam o profissional da saúde a negligenciar o autocuidado, dentre eles o desgaste e estresse ocasionado pelos plantões, o convívio com o sofrimento alheio, a exigência constante de atualização técnica, a permanente responsabilidade, a manutenção de um bom relacionamento com os pacientes e com a equipe, a falta de recursos humanos e materiais e a baixa remuneração. Estes aspectos interferem na qualidade de vida mesmo após o horário de trabalho ${ }^{26}$.

Todos os relatos confirmam a negligência no autocuidado, e os motivos estão relacionados à carga excessiva de trabalho, à má remuneração, que obriga o residente a realizar plantões em outra instituição, e ao fato de a residência ser uma preparação para a vida profissional, com uma carga intensa de estudo e busca por experiência ${ }^{27}$. 
"residência é uma época única que a gente tem de estudar e às vezes precisa trabalhar um pouquinho, a bolsa não é tão grande assim... a gente se negligencia um pouco... [os residentes] trabalham demais e acabam esquecendo deles mesmos, da família, do bem-estar". (R4)

"não tenho muito cuidado comigo mesmo". (R6)

"a carga horária nossa é bem puxada... a gente não tem muito tempo livre". (R9)

"Faço uns plantões [em outra instituição], faço uns bicos lá. A bolsa não dá pra sobreviver". (R5)

Estudos demonstram que o período da residência é muito difícil para os residentes. As queixas principais são: grande carga horária de trabalho, bolsa insuficiente, falta de tempo para estudar e dificuldades de alimentação, entre outras ${ }^{23}$.

O medo de cometer erros, a pressão do trabalho, a fadiga física são responsáveis pela elevada taxa de estresse e deficiências no autocuidado do médico residente. A má remuneração o leva a realizar plantões em outras instituições, trabalhando nas horas de folga. É comum o fato de o residente, principalmente o R1, trabalhar mais que as 60 horas semanais permitidas pela legislação ${ }^{23}$.

A falha no autocuidado pode gerar repercussões no cuidado ao paciente e na equipe de trabalho, além de aumentar o desgaste físico:

\footnotetext{
"o que a gente faz do nosso cuidado pessoal está sendo transmitido para o paciente e para toda a equipe com que você está trabalhando". (R3)

"você está cansado mesmo, acaba interferindo sim". (R6)

"no dia em que eu durmo muito pouco, ou faço muito plantão seguido, isso pode atrapalhar". (R8)
}

As repercussões no cuidado com o paciente citadas pelos residentes são nervosismo, falta de paciência, diminuição da criatividade e do humor, além de maior probabilidade de cometer erros na técnica anestésica:

\footnotetext{
"muitas vezes, eu já chego estressado, e isso se reflete porque aquela atenção que você ia dispensar para o seu paciente, você não dispensa, você já chega bravo". (R1)

"você não fica com paciência de ficar conversando com o paciente... Você não fica mais humorado ou tão criativo para pegar e tentar agradar o paciente para ele confiar em você". (R6) "a gente mexe muito com medicação, com diluição, entendeu?... fico mais propenso a cometer erros". (R8)
}

Estudos sobre a latência ao sono dos residentes em anestesiologia mostram que a fadiga e a privação do sono prejudicam o desempenho no trabalho, o raciocínio, a criatividade e a aprendizagem. Apontam que os residentes que tiveram seus períodos de sono impedidos por alguma atividade profissional ficam mais expostos a uma carga excessiva de trabalho, o que diminui sua capacidade de observação e de resposta rápida a eventos inesperados durante a cirurgia, podendo ocasionar complicações importantes ${ }^{28}$.

Ao se identificar o processo de trabalho, observa-se em alguns relatos a transformação do ser médico idealizado pelo discente durante a graduação e a residência médica, após maior maturidade profissional e emocional:

"É diferente eu hoje do eu de um ano atrás. Eu era muito mais animado que hoje". (R6)

"eu sempre gostei da relação médico-paciente, o negócio é que no começo eu sentia mais falta que agora... estou me acostumando à batida, me acostumando ao estilo de trabalho". (R2)

Os relatos demonstram que os jovens residentes idealizavam o ser médico durante o período da graduação. A idealização se apresenta por meio de investimento narcísico, fantasias, intimidade, história pessoal, capital simbólico e também da realidade ${ }^{9}$. No entanto, percebe-se que essa idealização torna-se impossível perante as incompatibilidades enfrentadas no ensino, prática e observação no período da residência. Os residentes demonstram sinais de esgotamento e desânimo. Com o passar dos anos, evidencia-se um desencanto com o processo vivenciado, em relação ao alcance global de suas metas ${ }^{29}$.

As tecnologias leves-duras e duras (tecnociência) levam o residente a realizar um trabalho mecânico, apoiado em rotinas preestabelecidas, passadas por manuais e pelos tutores, sendo, então, considerado um "trabalho morto". Mas durante a relação médico-paciente, no agir do médico, colocando em uso a "valise" das tecnologias leves, o processo muda. O residente pode, então, identificar as reais necessidades dos pacientes e, deixando em segundo plano as tecnologias duras, interferindo de acordo com seu raciocínio clinico, é capaz de gerar um cuidado que atinge o usuário de forma cada vez mais profunda ${ }^{8}$.

A residência médica bem estruturada representa o pilar básico da formação médica para elevar a assistência médica a padrões de excelência. $\mathrm{O}$ trabalho do residente deve ser visto como um investimento não só individual, dele próprio, mas de todos, dos serviços e dos preceptores, visando à qualidade da formação técnica, científica, social e ética, mantendo o atendimento eficaz das necessidades dos pacientes ${ }^{23}$.

\section{CONSIDERAÇÕES FINAIS}

A escolha da especialidade se dá pela proximidade com a medicina intensiva, pela dedicação exclusiva a um único paciente 
e pelo interesse em analgesia. O residente considera importante o compartilhamento do cuidado com outros profissionais, mas este é difícil, pois a anestesiologia é uma especialidade muito específica. O compartilhamento do cuidado com a equipe de enfermagem se dá por meio da delegação e cobrança de resultados, e mostra também uma parceria na ação de observar e atender o paciente.

Em relação ao acompanhamento docente, os residentes estão satisfeitos com a proximidade física, a orientação e auxílio durante os procedimentos, mas insatisfeitos devido a deficiências na área acadêmica e à falta de tempo para discutir temas relevantes à especialidade.

Os residentes participantes desta pesquisa relataram negligência total ou parcial com o autocuidado e apontaram como motivos a extensa carga horária e a realização de plantões em outros serviços, para complementação da bolsa. Eles consideram que seu autocuidado tem repercussões no cuidado com o paciente e no relacionamento com a própria equipe de trabalho. Por fim, relataram que houve uma mudança no "ser médico" idealizado por eles durante o período da graduação, surgindo certo desencanto com a medicina.

É necessário repensar a forma como a residência médica está estruturada, aumentando o acompanhamento docente e as oportunidades de crescimento acadêmico dos residentes. É também necessário maior interesse em cumprir a carga horária do residente, respeitando seus períodos de descanso e possibilitando um autocuidado eficaz. Também é preciso realizar outros estudos sobre esta temática, ampliando os programas de residência estudados e cruzando informações das diversas instituições que possuem programas de residência médica, a fim de ampliar as discussões para a melhoria das condições de treinamento destes jovens médicos.

\section{REFERÊNCIAS}

1. Aragão PW, Prazeres JO, Aragão VMF, Martins CAS. Pressão arterial do anestesiologista durante o ato anestésico-cirúrgico no período matutino. Rev Bras Anestesiol. 2002;52(5).

2. Conselho Regional de Medicina do Estado do Rio de Janeiro. Manual do médico residente. $3^{\underline{a}}$ ed. atual. Rio de Janeiro:CREMERJ; 2008.

3. Caprara A, Rodrigues J. A relação médico-paciente: repensando o vínculo terapêutico. Ciênc Saúde Colet. 2004;9(1).

4. Fighera J, Viero EV. Vivências do paciente com relação ao procedimento cirúrgico: fantasias e sentimentos mais presentes. Rev SBPH. 2005;8(2):51-63.

5. Garnica AVM. Algumas notas sobre pesquisa qualitativa e fenomenologia. Interface Comum Saúde Educ. 1997;1(1):117.
6. Minayo MCS. O Desafio do Conhecimento. Pesquisa Qualitativa em Saúde. São Paulo/Rio de Janeiro: Hucitec-Abrasco;1999.

7. Martins J, Bicudo MAV. A pesquisa qualitativa em psicologia: fundamentos e recursos básicos. $5^{\mathrm{a}}$ ed. São Paulo: Centauro; 2005.

8. Merhy EE. Um ensaio sobre o médico e suas valises tecnológicas: contribuições para compreender as reestruturações produtivas do setor saúde. Interface Comum Saúde Educ. 2000;4(6).

9. Fiore MLM, Yazigi L. Especialidades médicas: estudo psicossocial. Psicol Reflex Crit. 2005; 18(2).

10. Neves FBCS, Vieira PSPG, Cravo EA, Portugal TS, Almeida MF, Brasil ISPS, et al. Motivos relacionados à escolha da medicina intensiva como especialidade por médicos residentes. Rev Bras Ter Intensiva. 2009;21(2):135-40.

11. Oliveira AR, Mendes FF, Oliveira M. Os clientes e a avaliação pré-operatória ambulatorial. Rev Bras Anestesiol. 2003;53(1).

12. Pereira MGA, Azevedo ES. A relação médico-paciente em Rio Branco/AC sob a ótica dos pacientes. Rev Assoc Med Bras. 2005;51(3).

13. Pinotti HW. Filosofia da Cirurgia. São Paulo: Editora OLM; 2008.

14. Rossi OS, Batista NA. O ensino da comunicação na graduação em medicina: uma abordagem. Interface Comum Saúde Educ. 2006;10(19).

15. Filho GRO. Rotinas de cuidados pós-anestésicos de anestesiologistas brasileiros. Rev Bras Anestesiol. 2003;53(4).

16. Kiuti VN, Costa AMC, Sakata RK. Seguimento de cateter peridural para analgesia pós-operatória Rev Bras Med. 2008;65(8):242-5.

17. Vecina Neto G, Reinhardt Filho W. Gestão de Recursos Materiais e de Medicamentos, volume 12. São Paulo: Faculdade de Saúde Pública da Universidade de São Paulo, 1998. (Série Saúde \& Cidadania)

18. Holanda AB, Dicionário Aurélio Escolar da Língua Portuguesa. Rio de Janeiro: Nova Fronteira; 1988.

19. Foucault M. Microfísica do Poder. Rio de Janeiro: Graal; 1993.

20. Guerreiro LT, Machado AC, Maravilha CA, Pereira MO, Novaes M. A visão antropológica do cuidado nos serviços de saúde. Arq Apadec. 2004;8.

21. Kluger MT, Laidlaw TK, Kruger N. Personality traits of anesthetists and physicians: an evaluation using the cloninger temperament and character inventory (TCI-125). Anaesthesia, 1999;54:926-35.

22. Ayres JRCM. O cuidado, os modos de ser (do) humano e as práticas de saúde. Saúde Soc.2004; 13(3). 
23. Pessoa JHL, Constantino CF. O médico residente como força de trabalho. Rev Soc Cardiol 2002;6:821-5.

24. Perim GL, Abdall IG, Silva RHA, Lampert JB, Stella RCR, Costa NMSC. Desenvolvimento docente e a formação de médicos. Rev Bras Educ Med. 2010;33(Supl. 1):70-82.

25. Chemello D, Manfroi WC, Machado CLB. O papel do preceptor no ensino médico e o modelo preceptoria em um minuto. Rev Bras Educ Med. 2009;33(4):664-660.

26. Martins MM. Qualidade de vida e capacidade para o trabalho dos profissionais em enfermagem no trabalho em turnos. Florianópolis; 2002. Mestrado [Dissertação] - Universidade Federal de Santa Catarina.

27. Pessoa JHL, Constantino CF. O médico residente como força de trabalho. Rev Soc Cardiol. 2002;6:821-5.

28. Mathias LAST, Christina MFC, Elizabeth PV, Joaquim EV, Marcelo LP. O plantão noturno em anestesia reduz a latência ao sono. Rev Bras Anestesiol. 2004;54(5).

29. Silva GSN. A construção do 'ser médico' e a morte: significados e implicações para a humanização do cuidado. São Paulo; 2007. Tese [Doutorado] — Universidade de São Paulo.

\section{CONTRIBUIÇÃO DOS AUTORES}

Leonel Alves do Nascimento contribuiu na elaboração do projeto de pesquisa, coleta de dados e transcrição das entrevistas, análise e compilação dos resultados, produção do artigo. Cibele Cristina Tramontini Orientou na produção do projeto de pesquisa, coleta e transcrição, análise dos resultados e elaboração do artigo. Mara Lúcia Garanhani orientou na produção do projeto de pesquisa, coleta e transcrição, análise dos resultados e elaboração do artigo.

\section{CONFLITO DE INTERESSES}

Declarou não haver.

\section{ENDEREÇO PARA CORRESPONDÊNCIA}

Leonel Alves do Nascimento

Rua Rio Grande do Sul, 649

Vila Matarazzo - Londrina

CEP 86026-080 PR

E-mail: leonel_lan@hotmail.com 